\title{
P2X7 receptor stimulates breast cancer cell invasion and migration via the AKT pathway
}

\author{
JIYI XIA ${ }^{1 *}$, XIAOLAN YU ${ }^{2 *}$, LI TANG $^{3},{\text { GANG } \mathrm{LI}^{4} \text { and TAO HE }}^{5}$ \\ ${ }^{1}$ Research Center for Drug and Functional Food, Luzhou Medical College, Luzhou, Sichuan 646000; \\ ${ }^{2}$ Department of Obstetrics and Gynecology, The Affiliated TCM Hospital of Luzhou Medical College, Luzhou, \\ Sichuan 646000; ${ }^{3}$ Experimental Medicine Center, and ${ }^{4}$ Department of Pediatrics, Affiliated Hospital of \\ Luzhou Medical College, Luzhou, Sichuan 646000; ${ }^{5}$ Department of Biochemistry, \\ Luzhou Medical College, Luzhou, Sichuan 646000, P.R. China
}

Received December 24, 2014; Accepted March 20, 2015

DOI: 10.3892/or.2015.3979

\begin{abstract}
Purinergic signaling has been implicated in the regulation of many cellular processes. A high concentration of ATP has been observed in the tumor microenvironment, suggesting a possible role of extracellular ATP in tumor progression. The $\mathrm{P} 2 \mathrm{X} 7$ receptor, which belongs to the ligand-gated ion channel receptor family, is involved in tumor development and metastasis. In the present study, we found that extracellular ATP stimulated the invasion and migration of human T47D breast cancer cells, in a dose-dependent manner. BzATP (ATP analogue), but not ADP, also promoted invasion and migration. We further found that the $\mathrm{P} 2 \mathrm{X} 7$ receptor was highly expressed in the T47D cells. After knockdown of the $\mathrm{P} 2 \mathrm{X} 7$ receptor, ATP-stimulated invasion and migration were markedly inhibited. Moreover, activation of the P2X7 receptor by ATP downregulated the protein level of E-cadherin and upregulated the production of MMP-13. In addition, ATP time-dependently induced the activation of AKT via the $\mathrm{P} 2 \mathrm{X} 7$ receptor, and the AKT pathway was required for the ATP-mediated invasion and migration. Taken together, our results revealed that activation of the $\mathrm{P} 2 \mathrm{X} 7$ receptor by ATP promotes breast cancer cell invasion and migration, possibly via activation of the AKT pathway and regulation of E-cadherin and MMP-13 expression. Therefore, the $\mathrm{P} 2 \mathrm{X} 7$ receptor may be a useful therapeutic target for the treatment of breast cancer.
\end{abstract}

\section{Introduction}

Purinergic signaling acts as an important pathway in the regulation of cell growth, differentiation and development (1).

Correspondence to: Dr Tao He, The Institute of Cancer Research, Luzhou Medical College, 319 Zhong Shan Road, Luzhou, Sichuan 646000, P.R. China

E-mail: taohe1209@163.com

${ }^{*}$ Contributed equally

Key words: $\mathrm{P} 2 \mathrm{X} 7$ receptor, ATP, invasion, migration, breast cancer, AKT pathway
Extracellular ATP, which is widely distributed in the tumor microenvironment, has been reported to be involved in the progression of cancer (2). ATP acts through P2 receptors, which are further categorized as $\mathrm{P} 2 \mathrm{X}$ and $\mathrm{P} 2 \mathrm{Y}$ receptors. $\mathrm{P} 2 \mathrm{Y}$ receptors belong to the $\mathrm{G}$-protein coupled receptors, while $\mathrm{P} 2 \mathrm{X}$ receptors belong to the ligand-gated ion channel receptors. To date, seven $\mathrm{P} 2 \mathrm{X}$ receptor subtypes (P2X1-7) and eight $\mathrm{P} 2 \mathrm{Y}$ receptor subtypes (P2Y1, P2Y2, P2Y4, P2Y6, P2Y11, P2Y12, $\mathrm{P} 2 \mathrm{Y} 13$ and P2Y14) have been cloned in human cells (3). As one subtype of the $\mathrm{P} 2 \mathrm{X}$ receptors, the $\mathrm{P} 2 \mathrm{X} 7$ receptor has been found to be highly expressed in many types of cancers, such as acute myelogenous leukemia (AML), acute lymphoblastic leukemia (ALL), chronic myelogenous leukemia (CML) and thyroid papillary cancer $(4,5)$. However, the level of the $\mathrm{P} 2 \mathrm{X} 7$ receptor is low in tissues of complex hyperplasia with atypia or in endometrial adenocarcinoma and uterine epithelial cancer $(6,7)$.

Breast cancer is one of the most common cancers among women worldwide. Advancements in treatment including surgery, chemotherapy and radiotherapy have increased the overall survival rate of breast cancer patients (8). However, invasion and metastasis remain the major reasons for breast cancer-related mortality (9). One study reported that P2X7 receptor activation participated in the SK3 channel- and cystein cathepsin-dependent cancer cell invasiveness in MDA-MB435 s breast cancer cells (10), but the role of the $\mathrm{P} 2 \mathrm{X} 7$ receptor in breast cancer cell invasion and metastasis requires further clarification.

In the present study, we identified that $\mathrm{P} 2 \mathrm{X} 7$ receptor activation via extracellular ATP promoted the invasion and migration of T47D breast cancer cells. We also elucidated the function of the AKT pathway in the P2X7-mediated cell invasion and migration.

\section{Materials and methods}

Reagents. ATP, BzATP, ADP, P2X inhibitor APPDS and AKT inhibitor LY294002 were obtained from Sigma Chemical Co. (St. Louis, MO, USA). Antibodies to E-cadherin and $\beta$-actin were obtained from Santa Cruz Biotechnology (Santa Cruz, CA, USA). Antibodies to phospho-AKT and AKT were obtained from Cell Signaling Technology (Danvers, MA, USA). 
Cell culture. Human T47D breast cancer cells were obtained from the American Type Culture Collection (ATCC; Manassas, VA, USA) and were maintained in RPMI-1640 medium, supplemented with $10 \%$ fetal bovine serum (FBS), $100 \mathrm{mg} / \mathrm{ml}$ streptomycin, $100 \mathrm{U} / \mathrm{ml}$ penicillin and $2 \mathrm{mM} \mathrm{L-glutamine.}$ Cells were grown at $37^{\circ} \mathrm{C}$ in a humidified atmosphere of $95 \%$ air and $5 \% \mathrm{CO}_{2}$.

Transwell invasion assay. A 24-well cell culture Transwell chamber (Corning Costar, San Diego, CA, USA) was used to analyze the cell invasion capacity. The filters of the upper inserts were coated with Matrigel before being used. The upper inserts were seeded with $1 \times 10^{5}$ cells $/ 200 \mu \mathrm{l}$ in RPMI-1640 medium and the lower inserts were filled with RPMI-1640 medium, supplemented with 20\% FBS. After stimulation with different nucleotides (ATP, BzATP or ADP), the cells that invaded through the Matrigel and filters were fixed with methanol, and the nuclei were labeled with 4',6-diamidino-2-phenylindole (DAPI). Nuclei were counted using immunofluorescence microscopy (Nikon, Tokyo, Japan) at x200 magnification.

Transwell migration assay. Cell migration capacity was also determined using 24-well cell culture Transwell chambers (Corning Costar). Briefly, the upper inserts were seeded with $5 \times 10^{5}$ cells $/ 200 \mu 1$ in RPMI-1640 medium, and the lower inserts were filled with RPMI-1640 medium supplemented with $20 \%$ FBS as a chemoattractant. The cells were stimulated with or without the different nucleotides (ATP, BzATP or ADP). After an 18 -h incubation at $37^{\circ} \mathrm{C}$, the migrated cells were fixed with methanol, and the nuclei were labeled with DAPI. Finally, the nuclei were counted in seven random fields using immunofluorescence microscopy (Nikon) at x200 magnification.

RNA extraction, reverse transcription and real-time PCR. Total RNA was isolated from the T47D cells by TRIzol reagent (Invitrogen, Carlsbad, CA, USA). Then $2 \mu \mathrm{g}$ of RNA was reverse-transcribed into cDNA using the cDNA synthesis kit (Tiangen Biotech Co., Ltd., Beijing, China). Real-time PCR was performed with a SYBR-Green PCR kit (Tiangen Biotech) and the primers are listed in Table I. The fold-change in the expression of each objective gene relative to $\beta$-actin was calculated based on the $2^{-\Delta \Delta \mathrm{Ct}}$ method.

Small interfering RNA transfection. A P2X7 siRNA (siP2X7) was purchased from Shanghai Genechem Co., Ltd. (Shanghai, China), with the sequence of 5'-CCGAGAAACAGGCGA UAAU-3'. A scramble sequence not targeting any known gene was used as a control siRNA ( $\mathrm{siCtrl})$. T47D cells were plated in 24-well plates at the density of $1 \times 10^{4}$ cells $/ \mathrm{ml}$. Six hours later, the cells were transfected with siP $2 X 7$ or siCtrl using Lipofectamine 2000 (Invitrogen). After $36 \mathrm{~h}$ of transfection, real-time PCR was performed to assess the knockdown efficiency.

Western blot analysis. The cells were stimulated with or without the different nucleotides (ATP, BzATP or ADP) for various times, and the inhibitors were applied $30 \mathrm{~min}$ before ATP stimulation when the inhibitors were used. The cells were lysed in ice-cold RIPA buffer containing protease and
Table I. Real-time PCR primers.

\begin{tabular}{ll}
\hline Gene & \multicolumn{1}{c}{ Sequence (5'-3') } \\
\hline P2X1 & GGCTGACTACGTCTTCCCAG \\
& GCGCAGTAGCCTTGAGTCT \\
P2X2 & AGCTGGGCTTTATCGTGGAGA \\
& TTGGGGTTGCACTCCGATG \\
P2X3 & AGTCGGTGGTTGTGAAGAGC \\
& AGCCTTCTCGTGCAAGAAAAC \\
P2X4 & CTACCAGGAAACTGACTCCGT \\
& GGTATCACATAATCCGCCACAT \\
P2X5 & CTGTCGCTGTTCGACTACAAG \\
& CCCATACGACCAGGTACGC \\
P2X6 & GAACCCCAGTTTTCCATCATCA \\
& GGCGTCACAAGGAAGTTGGT \\
P2X7 & TATGAGACGAACAAAGTCACTCG \\
& GCAAAGCAAACGTAGGAAAAGAT \\
MMP-13 & ACTGAGAGGCTCCGAGAAATG \\
& GAACCCCGCATCTTGGCTT \\
& AGCGCGGCTACAGCTTCA \\
& CGTAGCACAGCTTCTCCTTAAT \\
\end{tabular}

phosphatase inhibitors (Applygen Technologies Inc., Beijing, China). Protein concentrations were determined with the BCA protein assay kit (Applygen Technologies). Then fifty micrograms of proteins were separated on $10 \%$ SDS gel electrophoresis and transferred to a PVDF membrane. After blocking with 5\% BSA in buffered saline, the membrane was further probed with primary antibodies overnight at $4^{\circ} \mathrm{C}$, and then incubated with the secondary antibodies for $1 \mathrm{~h}$ at room temperature. The immunoreactive bands were detected using ECL reagents (Applygen Technologies).

ELISA assay. After stimulation with or without ATP, the supernatant was collected and centrifuged at 10,000 $\mathrm{x} g$ for $15 \mathrm{~min}$ at $4^{\circ} \mathrm{C}$. The MMP-13 ELISA kit was purchased from Invitrogen (Carlsbad, CA, USA) and used to measure the protein level of MMP-13, according to the manufacturer's instructions.

Analysis of data. Experiments were repeated at least three times. Data are expressed as the means \pm SD, and were analyzed using the Student's t-test. Statistical significance is indicated when $\mathrm{P}<0.05$.

\section{Results}

Extracellular ATP promotes the invasion and migration of breast cancer cells. To determine the effect of ATP on the invasion and migration of breast cancer cells, we performed Transwell invasion and migration assays in the T47D cells. The results showed that ATP produced a concentrationdependent (100-300 $\mu \mathrm{M})$ increase in the invasion and migration capacities of the T47D cells, with a maximal effect 
A

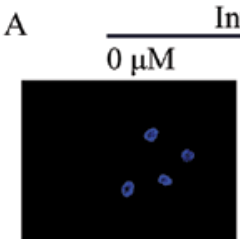

$200 \mu \mathrm{M}$

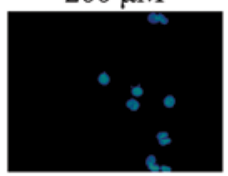

$300 \mu \mathrm{M}$

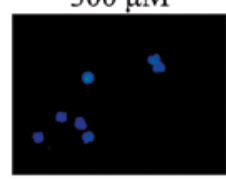

B

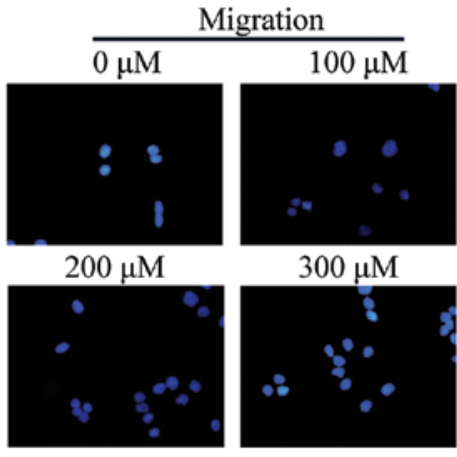

C

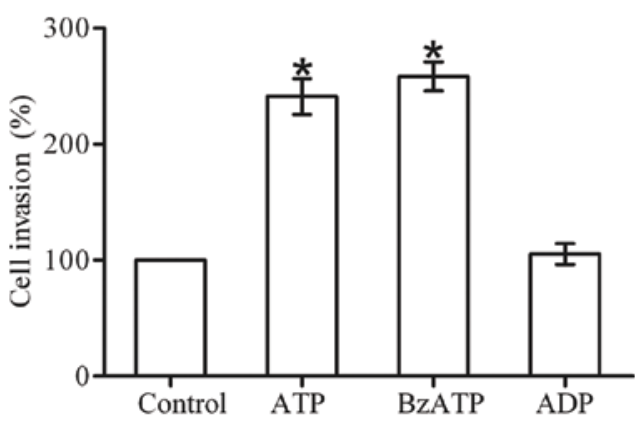

D
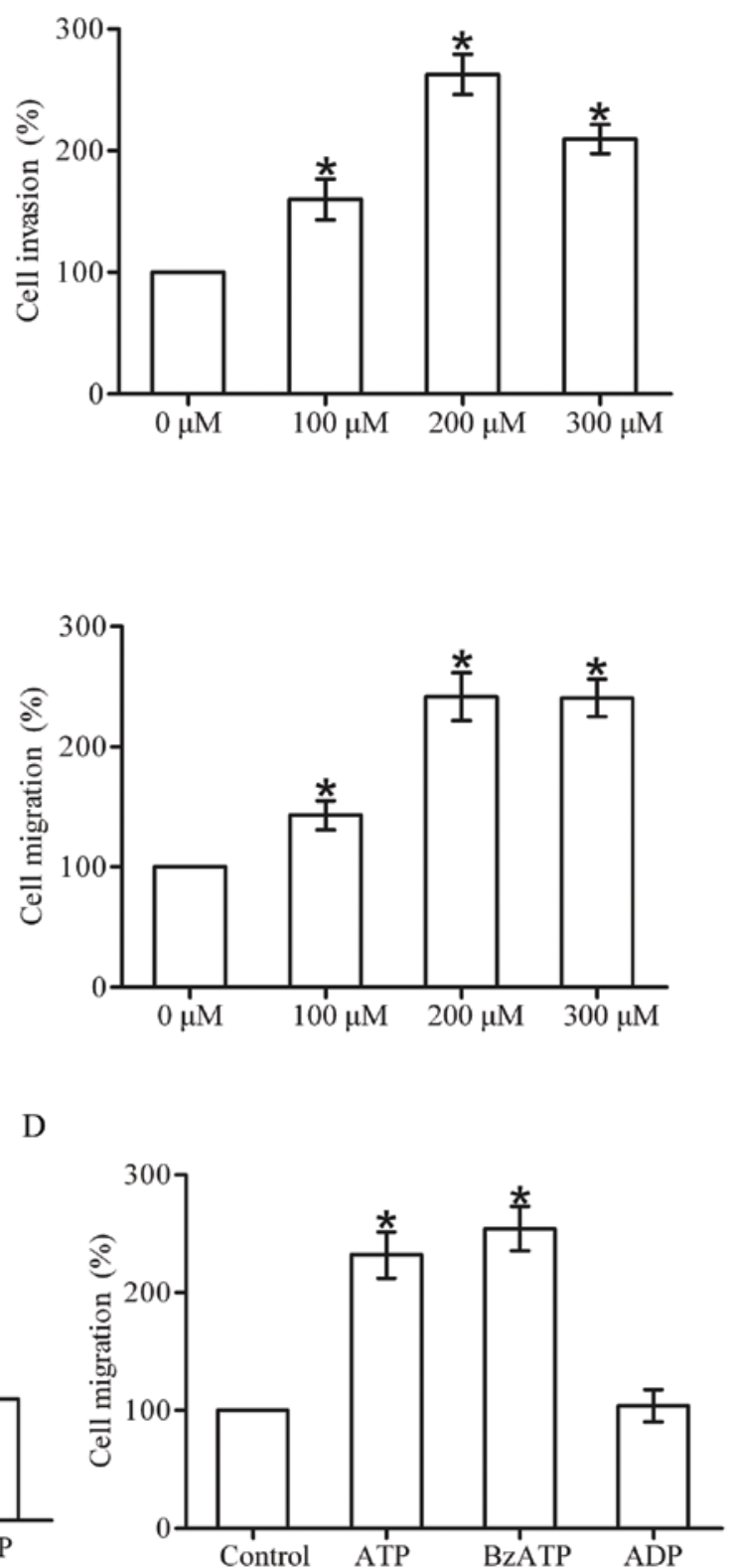

Figure 1. Effect of purinergic nucleotides on breast cancer cell invasion and migration. Human breast cancer T47D cells were stimulated with different concentrations of ATP. (A) Effect of ATP on the invasion of T47D cells after an 18-h incubation with ATP. (B) Effect of ATP on the migration of T47D cells after an 18-h incubation with ATP. (C) Invasion of T47D cells was observed after an 18-h incubation with ATP (200 $\mu$ M), BzATP (200 $\mu$ M) or ADP (200 $\mu$ M). (D) Migration of T47D cells was observed after an $18-\mathrm{h}$ incubation with ATP $(200 \mu \mathrm{M})$, BzATP $(200 \mu \mathrm{M})$ or ADP $(200 \mu \mathrm{M})$; ${ }^{*} \mathrm{P}<0.05$, compared with the controls.

occurring at $200 \mu \mathrm{M}$ (Fig. 1A and B). Therefore, subsequent experiments were carried out using $200 \mu \mathrm{M}$. Furthermore, the ATP analogue BzATP also promoted the invasion and migration of the T47D cells. However, ADP had little effect on the invasion and migration (Fig. 1C and D). Together, these data suggest that extracellular ATP promotes the invasion and migration of breast cancer cells.

Effect of $P 2 X 7$ receptor activation on the invasion and migration of breast cancer cells. Next, we found that PPADS $(100 \mu \mathrm{M})$, a non-selective $\mathrm{P} 2 \mathrm{X}$ receptor antagonist, attenuated the ATP-induced invasion and migration of the T47D cells (Fig. 2A and B). Seven P2X receptor subtypes (P2X1-7) have been cloned in human cells, and the $\mathrm{P} 2 \mathrm{X} 7$ receptor has been reported to play an important role in tumor progression (11).
Using real-time PCR, we found that the $\mathrm{P} 2 \mathrm{X} 7$ receptor was significantly expressed in the T47D cells (Fig. 2C). Thus, we silenced the expression of $\mathrm{P} 2 \mathrm{X} 7$ receptor in the T47D cells by transfection of siRNA (Fig. 2D), and then investigated the effect of P2X7 knockdown on cell invasion and migration. We found that knockdown of the $\mathrm{P} 2 \mathrm{X} 7$ receptor markedly inhibited the invasion and migration of the T47D cells promoted by ATP stimulation (Fig. 2E and F), indicating the involvement of the $\mathrm{P} 2 \mathrm{X} 7$ receptor in breast cancer cell invasion and migration.

Activation of the $P 2 X 7$ receptor affects the levels of $E$-cadherin and $M M P-13$. E-cadherin is essential for tumor invasion and metastasis (12). Using western blot analysis, we found that ATP and its analogue BzATP downregulated the protein level 
A

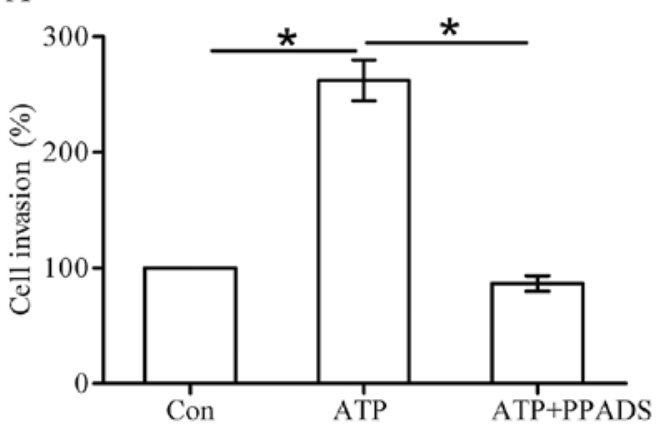

$\mathrm{C}$

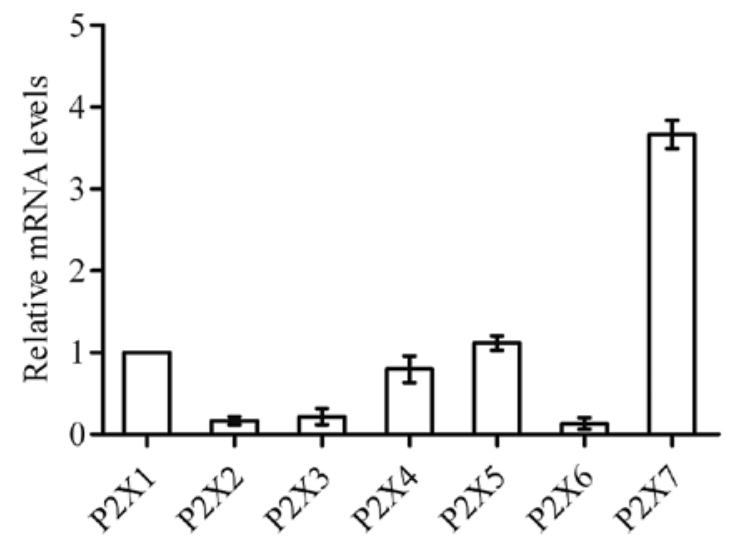

B

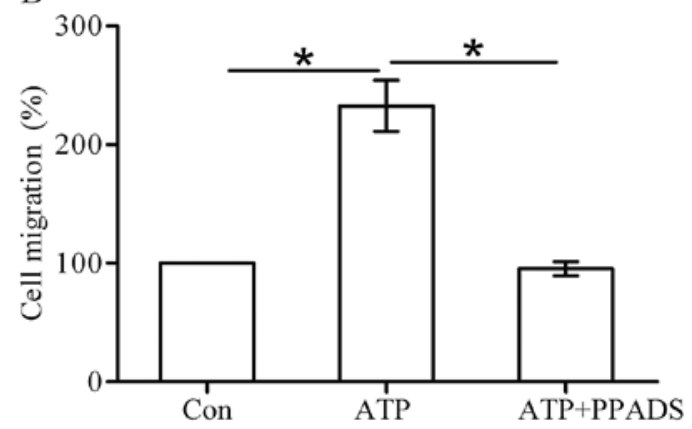

D

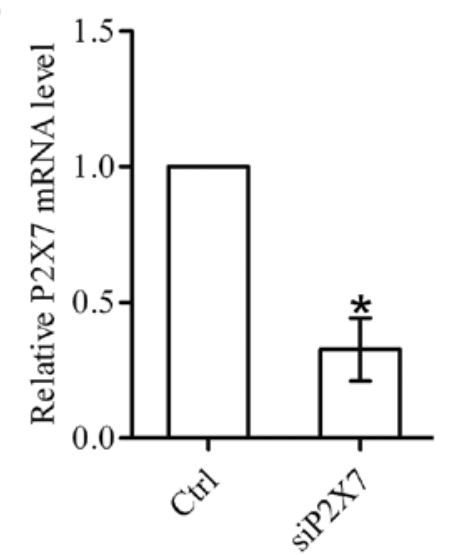

E

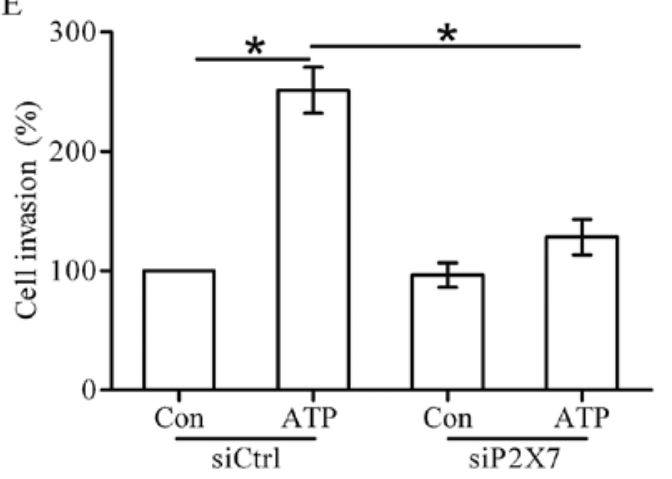

$\mathrm{F}$

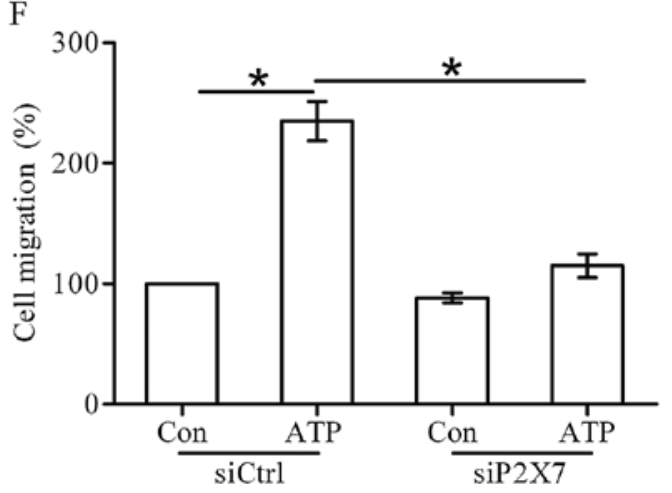

Figure 2. Involvement of the P2X7 receptor in ATP-mediated breast cancer cell invasion and migration. (A and B) T47D cells were pretreated with PPADS (P2X7 inhibitor, $100 \mu \mathrm{M}$ ) for $30 \mathrm{~min}$, and then stimulated with or without ATP. Cell invasion and migration abilities were determined by Transwell invasion and migration assays. (C) The mRNA expression level of P2X receptor subtypes (P2X1-7) were detected by real-time PCR. (D) T47D cells were transfected with control siRNA (siCtrl) or P2X7 siRNA (siP2X7), and knockdown efficiency was examined by real-time PCR. (E) Effect of P2X7 receptor knockdown on ATP-induced invasion of T47D cells. (F) Effect of P2X7 receptor knockdown on ATP-induced migration of T47D cells; *P<0.05.

of E-cadherin in the T47D cells, whereas ADP did not affect the protein level of E-cadherin (Fig. 3A). MMP-13 plays an important role in tumor invasion. In the present study, realtime PCR and ELISA assay showed that ATP and its analogue BzATP increased the expression and secretion of MMP-13 in the T47D cells. However, ADP did not affect the production of MMP-13 (Fig. 3B and C).

Extracellular ATP regulates the expression of E-cadherin and $M M P-13$ via the P2X7 receptor. As shown in Fig. 4A, after stimulation of ATP, the expression of E-cdherin was decreased in the control siRNA (siCtrl) cells. However, the expression of E-cadherin did not show any change in the P2X7 siRNA ( $\mathrm{siP} 2 \mathrm{X} 7)$ cells stimulated with ATP. Furthermore, ATP increased the expression and secretion of MMP-13 in the siCtrl cells, whereas ATP stimulation had little effect on MMP-13 production in the siP2X7 cells (Fig. 4B and C). These findings imply that activation of the $\mathrm{P} 2 \mathrm{X} 7$ receptor by ATP decreases the expression level of E-cadherin and MMP-13 in breast cancer cells.

Activation of the $P 2 X 7$ receptor by ATP induces the AKT pathway in breast cancer cells. AKT, a pivotal kinase in the cell signaling pathway, participates in tumor metastasis and development (13). Therefore, we examined whether ATP could stimulate the activation of the AKT pathway in breast cancer cells. As shown in Fig. 5A, ATP $(200 \mu \mathrm{M})$ time-dependently stimulated a marked increase in the level of phosphorylated AKT in the T47D cells, and peak activation occurred at $30 \mathrm{~min}$. Moreover, western blot analysis showed that the ATP-induced 


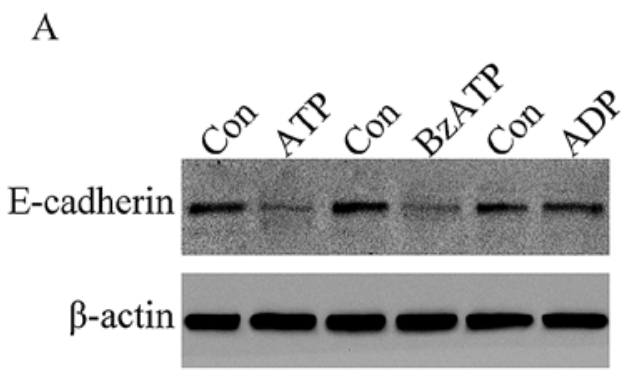

B

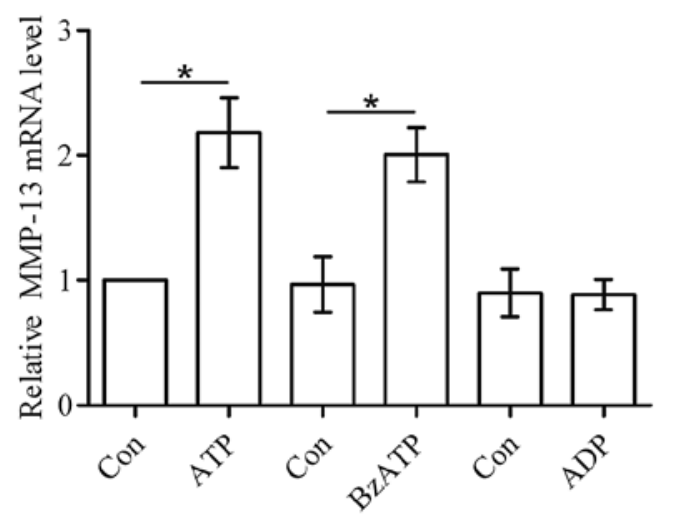

C
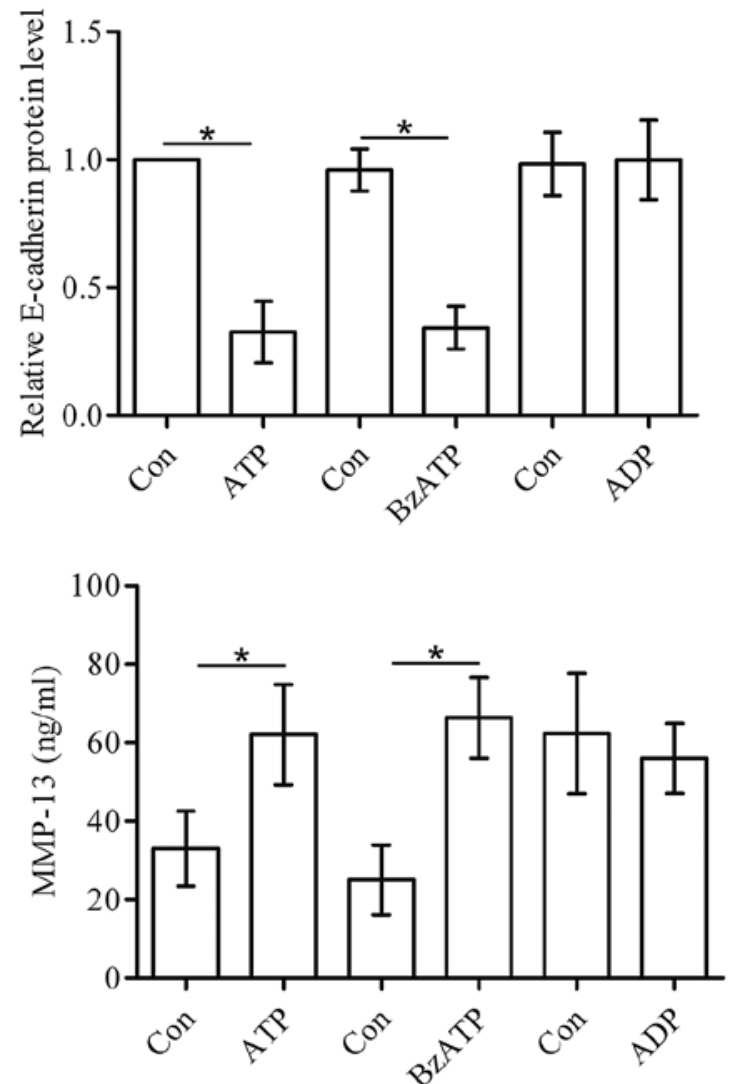

Figure 3. P2X7 receptor activation participates in the regulation of E-cadherin and MMP-13 expression in breast cancer cells. (A) T47D cells were incubated with ATP $(200 \mu \mathrm{M})$, BzATP $(200 \mu \mathrm{M})$ or ADP $(200 \mu \mathrm{M})$ for $18 \mathrm{~h}$, and the protein level of E-cadherin was detected by western blot analysis. (B) T47D cells were incubated with ATP $(200 \mu \mathrm{M})$, BzATP $(200 \mu \mathrm{M})$ or ADP $(200 \mu \mathrm{M})$ for $18 \mathrm{~h}$, and the mRNA level of MMP-13 was detected by real-time PCR. (C) T47D cells were incubated with ATP $(200 \mu \mathrm{M})$, BzATP $(200 \mu \mathrm{M})$ or ADP $(200 \mu \mathrm{M})$ for $18 \mathrm{~h}$, and the secretion of MMP-13 was detected by ELISA assay; ${ }^{*}<0.05$.

A
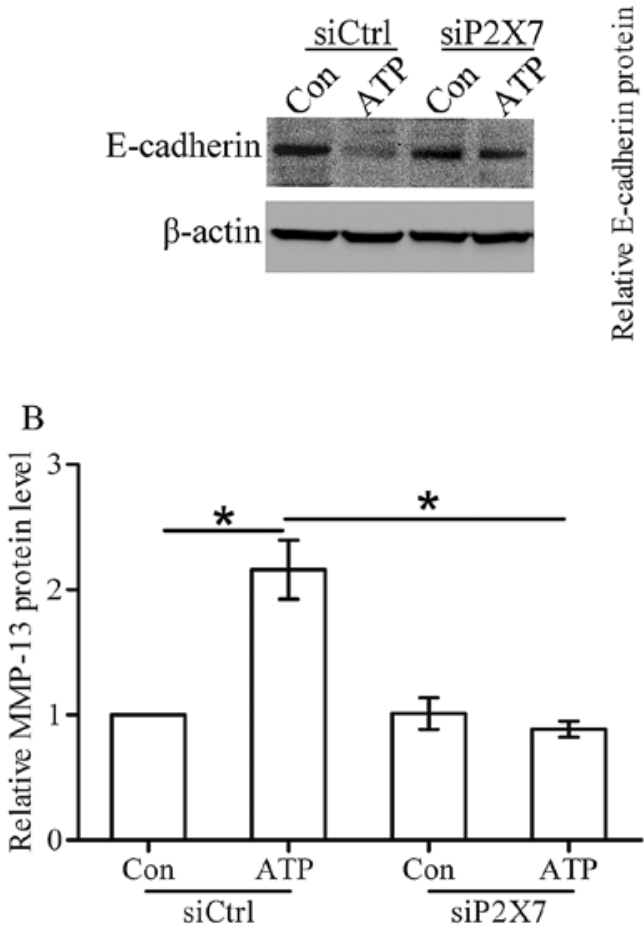

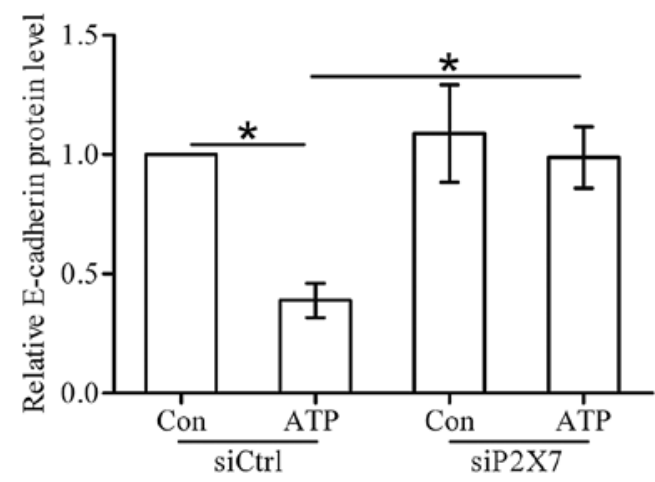

$\mathrm{C}$

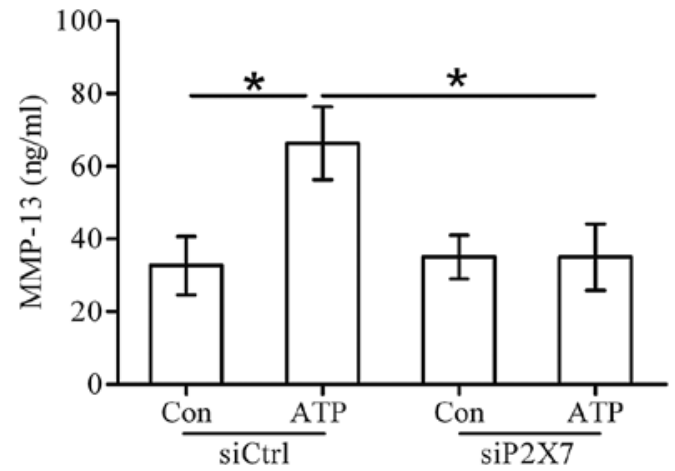

Figure 4. Effect of P2X7 receptor knockdown on E-cadherin and MMP-13 expression. (A) Western blot analysis showing the protein level of E-cadherin upon ATP stimulation for $18 \mathrm{~h}$ in the siCtrl or siP2X7 cells. (B) Real-time PCR and (C) ELISA assay showing the expression and secretion of MMP-13 upon ATP stimulation for $18 \mathrm{~h}$ in the siCtrl or siP2X7 cells; ${ }^{*} \mathrm{P}<0.05$. 
A
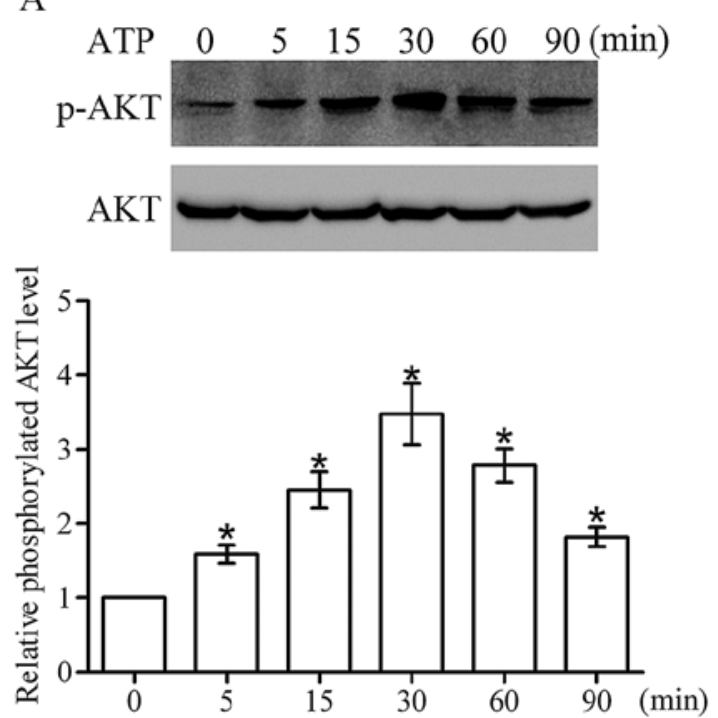

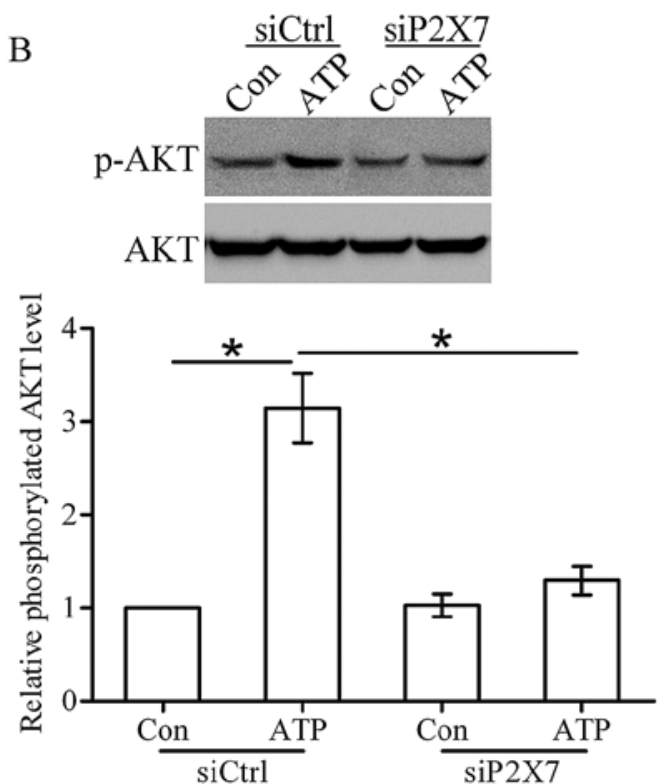

Figure 5. ATP activates the AKT pathway through the P2X7 receptor. (A) T47D cells were stimulated with $200 \mu \mathrm{M}$ ATP for 5, 15, 30, 60 or 90 min, and the level of phosphorylated AKT was detected by western blot analysis. (B) Western blot analysis showing the level of phosphorylated AKT upon ATP stimulation for $30 \mathrm{~min}$ in the siCtrl or siP2X7 cells; ${ }^{*} \mathrm{P}<0.05$.

A

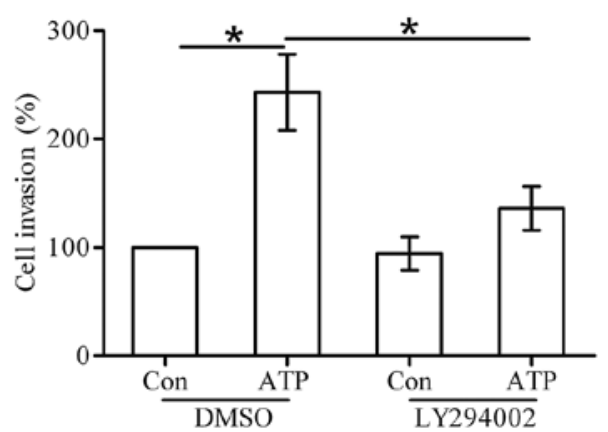

B

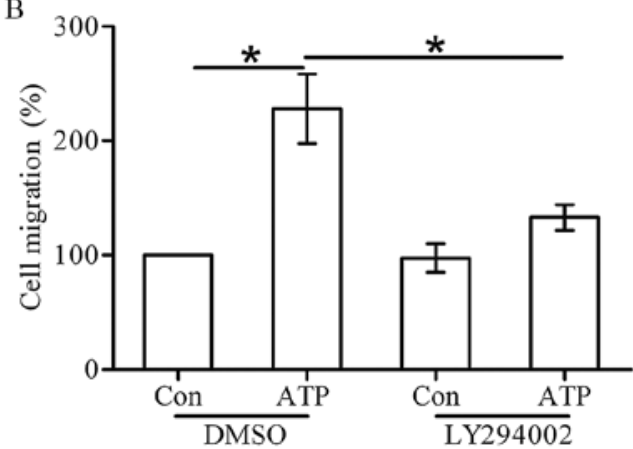

Figure 6. Role of the AKT pathway in ATP-induced breast cancer cell invasion and migration. T47D cells were pretreated with LY294002 (AKT inhibitor, $10 \mathrm{mM}$ ). (A and B) To assess the invasion and migration abilities, T47D cells were stimulated with or without ATP, and then subjected to Transwell invasion and migration assays; ${ }^{*} \mathrm{P}<0.05$.

activation of AKT was greatly inhibited after knockdown of the $\mathrm{P} 2 \mathrm{X} 7$ receptor (Fig. 5B), suggesting that the $\mathrm{P} 2 \mathrm{X} 7$ receptor contributes to the ATP-induced activation of the AKT pathway in breast cancer cells.

Effect of the AKT pathway on P2X7-mediated invasion and migration. To determine whether the $\mathrm{P} 2 \mathrm{X} 7$ receptorstimulated cell invasion and migration are mediated through the AKT pathway, T47D cells were pretreated with $10 \mathrm{mM}$ LY294002 for 30 min before ATP stimulation. Transwell invasion and migration assays showed that LY294002 inhibited the cell invasion and migration induced by ATP (Fig. 6A and B). These data confirm that the AKT pathway is required for the invasion and migration induced by ATP.

Effect of the AKT pathway on P2X7-mediated expression changes of E-cadherin and MMP-13. Western blot analysis showed that ATP stimulation decreased the protein level of E-cadherin in the DMSO-treated cells, whereas the effect of ATP on E-cadherin expression was attenuated in the LY294002-treated cells (Fig. 7A). Furthermore, real-time PCR and ELISA assay showed that ATP stimulation increased the expression and secretion of MMP-13 in the DMSO-treated cells, while in the LY294002-treated cells, this effect was significantly attenuated (Fig. 7B and C).

\section{Discussion}

Many reports have proved the important functions of purinergic signaling in tumor progression. In the present study, we examined the capability of $\mathrm{P} 2 \mathrm{X} 7$ receptor activation to induce breast cancer cell invasion and migration. We found that ATP and its analogue BzATP stimulated the invasion and migration of human breast cancer T47D cells. P2X receptor inhibitor PPADS suppressed the ATP-mediated cell invasion and migration. Furthermore, knockdown of the P2X7 receptor inhibited the invasion and migration stimulated by ATP. Altogether, our data suggest that activation of the P2X7 
A

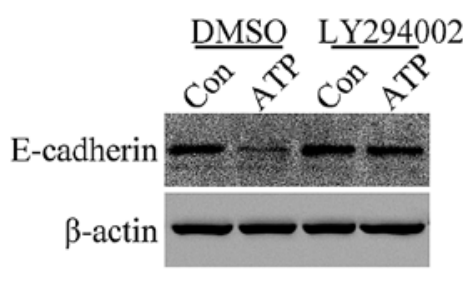

B

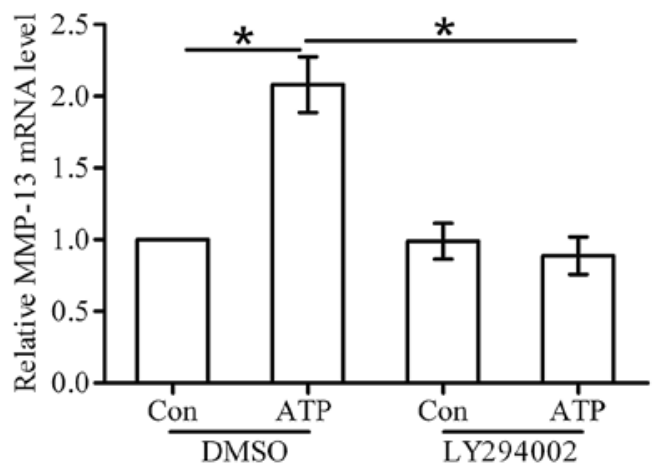

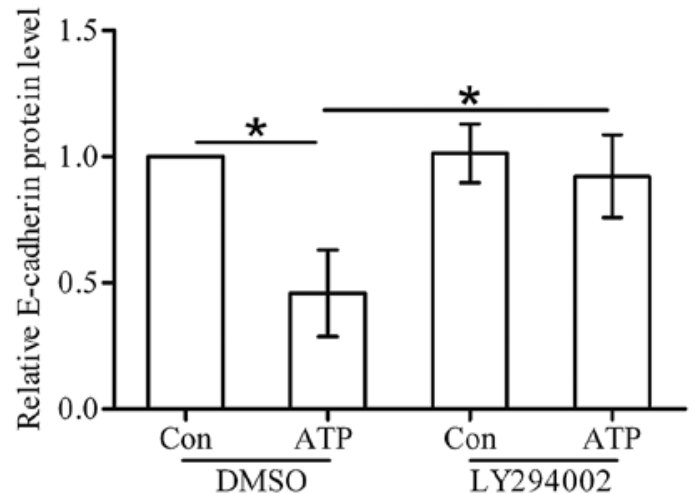

$\mathrm{C}$

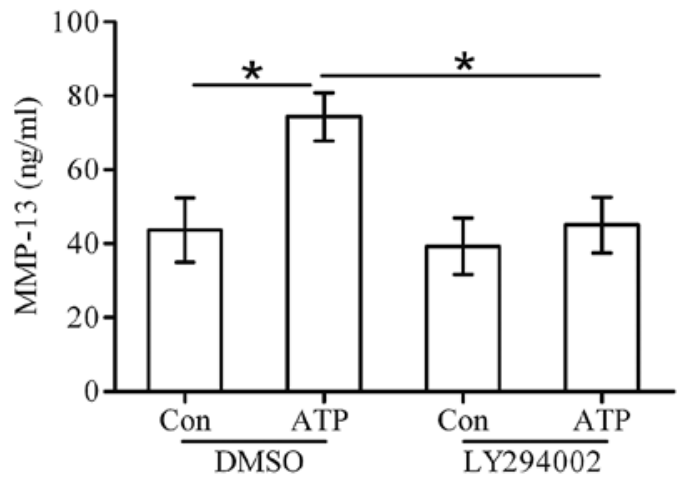

Figure 7. Role of the AKT pathway in the ATP-mediated expression changes of E-cadherin and MMP-13 in breast cancer cells. T47D cells were pretreated with LY294002 (AKT inhibitor, $10 \mathrm{mM}$ ). (A) To assess the E-cadherin protein level, T47D cells were stimulated with or without ATP for $18 \mathrm{~h}$, and then subjected to western blot analysis. (B) To assess the MMP-13 mRNA level, T47D cells were stimulated with or without ATP for $18 \mathrm{~h}$, and then subjected to real-time PCR. (C) To assess the MMP-13 protein level, T47D cells were stimulated with or without ATP for $18 \mathrm{~h}$, and then subjected to ELISA assay; ${ }^{*} \mathrm{P}<0.05$.

receptor by ATP contributes to the invasion and migration of breast cancer cells.

Previously, studies have found that extracellular ATP stimulation leads to a decrease in the growth of tumor cells (14). Further studies showed that ATP participates in tumor motility, invasion and metastasis $(15,16)$. In the present study, we found that ATP dose-dependently increased the invasion and migration of T47D cells. We further found that BzATP also stimulated cell invasion and migration, whereas ADP stimulation did not affect the invasion and migration of T47D cells, confirming the involvement of ATP in regulating breast cancer cell invasion and migration. ATP functions via $\mathrm{P} 2$ receptors, which are divided into $\mathrm{P} 2 \mathrm{X}$ and $\mathrm{P} 2 \mathrm{Y}$ receptors. In the present study, we found that the $\mathrm{P} 2 \mathrm{X}$ receptor inhibitor PPADS could greatly suppress the ATP-induced cell invasion and migration, suggesting that $\mathrm{P} 2 \mathrm{X}$ receptors may participate in the invasion and migration of breast cancer cells. There are seven $\mathrm{P} 2 \mathrm{X}$ receptor subtypes (P2X1-7) that have been cloned in human cells. Using real-time PCR, we found that the P2X7 receptor was significantly expressed in the T47D cells. Studies have reported that expression of the $\mathrm{P} 2 \mathrm{X} 7$ receptor is elevated in thyroid papillary cancer, and is closely associated with poor prognostic factors and lymph node metastasis $(4,17,18)$. It was reported that activation of the $\mathrm{P} 2 \mathrm{X} 7$ receptor increased the growth of B16 melanoma cells in vitro and in vivo $(19,20)$ and influenced the motile activity of lung cancer cells (21). Jelassi et al (10) found that $\mathrm{P} 2 \mathrm{X} 7$ receptor activation enhanced SK3 channel- and cystein cathepsin-dependent cancer cell invasiveness of MDA-MB-435s breast cancer cells. In the present study, we found that the knockdown of the P2X7 receptor inhibited the ATP-mediated invasion and migration of T47D cells, further confirming that $\mathrm{P} 2 \mathrm{X} 7$ receptor activation promotes breast cancer cell invasion and migration.

Epithelial-mesenchymal transition (EMT) is essential for the invasion and metastasis of breast cancer cells (22). Davis et al (23) showed that ATP stimulated the expression of vimentin in MDA-MB-468 breast cancer cells, and Li et al (15) further found that ATP increased the protein levels of E-cadherin and Snail in prostate cancer cells, suggesting that ATP may affect the EMT process in tumor cells. E-cadherin, which is an important EMT-related marker in tumors, regulates cell-cell adhesion and is often weakly expressed in tumor cells (24). In the present study, we found that ATP and its analogue BzATP downregulated the expression of E-cadherin, but ADP had little effect on the expression of E-cadherin in breast cancer cells. Using siRNA technology, we confirmed that ATP stimulation decreased the protein level of E-cadherin via the $\mathrm{P} 2 \mathrm{X} 7$ receptor.

A member of the metalloproteinases (MMPs), MMP-13 plays a key role in regulating tumor invasion and metastasis. Many studies have reported that MMP-13 contributes to the bone metastasis of breast cancer $(25,26)$. It was reported that extracellular ATP stimulated MMP-13 mRNA expression in DU-145 prostate cancer cells (27). However, there is no report concerning the effect of the $\mathrm{P} 2 \mathrm{X} 7$ receptor on MMP-13 expression. Here, we found that activation of the $\mathrm{P} 2 \mathrm{X} 7$ receptor by 
ATP promoted the expression and secretion of MMP-13 in breast cancer cells.

Many intracellular signaling pathways can be activated by the $\mathrm{P} 2 \mathrm{X} 7$ receptor. Studies have confirmed that activation of the P2X7 receptor enhanced the proliferation of ovarian carcinoma cells via the AKT and ERK1/2 pathways (28), and mediated tumor cell death via PI3K/AKT and AMPKPRAS40-mTOR signaling pathways (29). In the present study, we found that activation of the P2X7 receptor by ATP timedependently induced the AKT pathway in the T47D cells. It is well known that the AKT pathway plays a vital role in tumor progression (30). The present study showed that blocking of the AKT pathway attenuated the effect of ATP on the invasion and migration in T47D cells. We further identified that inhibition of the AKT pathway suppressed the changes in P2X7-mediated E-cadherin and MMP-13 expression. These data indicate that activation of the $\mathrm{P} 2 \mathrm{X} 7$ receptor stimulates breast cancer cell invasion and migration via the AKT pathway.

In conclusion, the present study demonstrated that ATP stimulation promotes the invasion and migration of breast cancer cells via activation of the $\mathrm{P} 2 \mathrm{X} 7$ receptor. The function of the $\mathrm{P} 2 \mathrm{X} 7$ receptor may be triggered by activation of the AKT pathway and subsequent regulation of E-cadherin and MMP-13 expression. Thus, the $\mathrm{P} 2 \mathrm{X} 7$ receptor could act as a new target for the anticancer therapy of breast cancer.

\section{Acknowledgements}

The present study was supported by a grant from the Luzhou Administration of Science and Technology, no. 2014-S-44(5/8).

\section{References}

1. Burnstock G: Purinergic signalling: Pathophysiology and therapeutic potential. Keio J Med 62: 63-73, 2013.

2. Braganhol E, Wink MR, Lenz G and Battastini AM: Purinergic signaling in glioma progression. Adv Exp Med Biol 986: 81-102, 2013.

3. Burnstock G: Introduction: P2 receptors. Curr Top Med Chem 4: 793-803, 2004.

4. Solini A, Cuccato S, Ferrari D, Santini E, Gulinelli S, Callegari MG, Dardano A, Faviana P, Madec S, Di Virgilio F, et al: Increased $\mathrm{P} 2 \mathrm{X} 7$ receptor expression and function in thyroid papillary cancer: A new potential marker of the disease? Endocrinology 149: 389-396, 2008.

5. Zhang XJ, Zheng GG, Ma XT, Yang YH, Li G, Rao Q, Nie K and Wu KF: Expression of P2X7 in human hematopoietic cell lines and leukemia patients. Leuk Res 28: 1313-1322, 2004.

6. Li X, Qi X, Zhou L, Catera D, Rote NS, Potashkin J, AbdulKarim FW and Gorodeski GI: Decreased expression of P2X7 in endometrial epithelial pre-cancerous and cancer cells. Gynecol Oncol 106: 233-243, 2007.

7. Li X, Zhou L, Feng YH, Abdul-Karim FW and Gorodeski GI: The P2X7 receptor: A novel biomarker of uterine epithelial cancers. Cancer Epidemiol Biomarkers Prev 15: 1906-1913, 2006.

8. DeSantis C, Ma J, Bryan L and Jemal A: Breast cancer statistics, 2013. CA Cancer J Clin 64: 52-62, 2014.

9. Hanahan D and Weinberg RA: Hallmarks of cancer: The next generation. Cell 144: 646-674, 2011.

10. Jelassi B, Chantôme A, Alcaraz-Pérez F, Baroja-Mazo A, Cayuela ML, Pelegrin P, Surprenant A and Roger S: P2X(7) receptor activation enhances SK3 channels- and cystein cathepsin-dependent cancer cells invasiveness. Oncogene 30: 2108-2122, 2011

11. Sun SH: Roles of $\mathrm{P} 2 X 7$ receptor in glial and neuroblastoma cells: The therapeutic potential of $\mathrm{P} 2 \mathrm{X} 7$ receptor antagonists. Mol Neurobiol 41: 351-355, 2010.
12. Canel M, Serrels A, Frame MC and Brunton VG: E-cadherinintegrin crosstalk in cancer invasion and metastasis. J Cell Sci 126: 393-401, 2013.

13. Sheng S, Qiao M and Pardee AB: Metastasis and AKT activation. J Cell Physiol 218: 451-454, 2009.

14. Yang G, Zhang S, Zhang Y, Zhou Q, Peng S, Zhang T, Yang C, Zhu Z and Zhang F: The inhibitory effects of extracellular ATP on the growth of nasopharyngeal carcinoma cells via P2Y2 receptor and osteopontin. J Exp Clin Cancer Res 33: 53, 2014.

15. Li WH, Qiu Y, Zhang HQ, Liu Y, You JF, Tian XX and Fang WG: $\mathrm{P} 2 \mathrm{Y} 2$ receptor promotes cell invasion and metastasis in prostate cancer cells. Br J Cancer 109: 1666-1675, 2013.

16. Shi K, Queiroz KC, Stap J, Richel DJ and Spek CA: Proteaseactivated receptor-2 induces migration of pancreatic cancer cells in an extracellular ATP-dependent manner. J Thromb Haemost 11: 1892-1902, 2013.

17. Gu LQ, Li FY, Zhao L, Liu Y, Chu Q, Zang XX, Liu JM, Ning G and Zhao YJ: Association of XIAP and P2X7 receptor expression with lymph node metastasis in papillary thyroid carcinoma. Endocrine 38: 276-282, 2010

18. Kwon JH, Nam ES, Shin HS, Cho SJ, Park HR and Kwon MJ: P2X7 receptor expression in coexistence of papillary thyroid carcinoma with Hashimoto's thyroiditis. Korean J Pathol 48: 30-35, 2014.

19. Adinolfi E, Raffaghello L, Giuliani AL, Cavazzini L, Capece M, Chiozzi P, Bianchi G, Kroemer G, Pistoia V and Di Virgilio F: Expression of P2X7 receptor increases in vivo tumor growth. Cancer Res 72: 2957-2969, 2012.

20. Hattori F, Ohshima Y, Seki S, Tsukimoto M, Sato M, Takenouchi T, Suzuki A, Takai E, Kitani H, Harada H, et al: Feasibility study of B16 melanoma therapy using oxidized ATP to target purinergic receptor P2X7. Eur J Pharmacol 695: 20-26, 2012.

21. Takai E, Tsukimoto M, Harada H and Kojima S: Autocrine signaling via release of ATP and activation of $\mathrm{P} 2 \mathrm{X} 7$ receptor influences motile activity of human lung cancer cells. Purinergic Signal 10: 487-497, 2014.

22. Wang Y and Zhou BP: Epithelial-mesenchymal transition in breast cancer progression and metastasis. Chin J Cancer 30: 603-611, 2011.

23. Davis FM, Kenny PA, Soo ET, van Denderen BJ, Thompson EW, Cabot PJ, Parat MO, Roberts-Thomson SJ and Monteith GR: Remodeling of purinergic receptor-mediated $\mathrm{Ca}^{2+}$ signaling as a consequence of EGF-induced epithelial-mesenchymal transition in breast cancer cells. PLoS One 6: e23464, 2011.

24. Paredes J, Figueiredo J, Albergaria A, Oliveira P, Carvalho J, Ribeiro AS, Caldeira J, Costa AM, Simões-Correia J, Oliveira MJ, et al: Epithelial E- and P-cadherins: Role and clinical significance in cancer. Biochim Biophys Acta 1826: 297-311, 2012.

25. Morrison C, Mancini S, Cipollone J, Kappelhoff R, Roskelley C and Overall C: Microarray and proteomic analysis of breast cancer cell and osteoblast co-cultures: Role of osteoblast matrix metalloproteinase (MMP)-13 in bone metastasis. J Biol Chem 286: 34271-34285, 2011

26. Pivetta E,Scapolan M,Pecolo M, Wassermann B,Abu-RumeilehI, Balestreri L, Borsatti E, Tripodo C, Colombatti A and Spessotto P: MMP-13 stimulates osteoclast differentiation and activation in tumour breast bone metastases. Breast Cancer Res 13: R105, 2011.

27. Zhang Y, Gong LH, Zhang HQ, Du Q, You JF, Tian XX and Fang WG: Extracellular ATP enhances in vitro invasion of prostate cancer cells by activating Rho GTPase and upregulating MMPs expression. Cancer Lett 293: 189-197, 2010.

28. Vázquez-Cuevas FG, Martínez-Ramírez AS, Robles-Martínez L, Garay E, García-Carrancá A, Pérez-Montiel D, CastañedaGarcía C and Arellano RO: Paracrine stimulation of P2X7 receptor by ATP activates a proliferative pathway in ovarian carcinoma cells. J Cell Biochem 115: 1955-1966, 2014.

29. Bian S, Sun X, Bai A, Zhang C, Li L, Enjyoji K, Junger WG, Robson SC and Wu Y: P2X7 integrates PI3K/AKT and AMPKPRAS40-mTOR signaling pathways to mediate tumor cell death. PLoS One 8: e60184, 2013.

30. Lauring J, Park BH and Wolff AC: The phosphoinositide3-kinase-Akt-mTOR pathway as a therapeutic target in breast cancer. J Natl Compr Canc Netw 11: 670-678, 2013. 